\title{
OCCURRENCE OF A NEW CEPHALOSPOROATE IN A CULTURE BROTH OF A CEPHALOSPORIUM ACREMONIUM MUTANT
}

\author{
Yukio Fujisawa and Toshiniko Kanzaki \\ Microbiological Research Laboratories, Central Research Division, \\ Takeda Chemical Industries, Ltd., Yodogawa-ku, Osaka 532, Japan \\ (Received for publication February 12, 1975)
}

\begin{abstract}
A new metabolite was isolated from the culture filtrate of a deacetylcephalosporin C-producing mutant, derived from Cephalosporium acremonium ATCC 14553, by means of adsorption on activated carbon, column chromatography on DEAE-Sephadex A-25 and gel filtration through a Sephadex G-10 column. The compound was identified as D-5-amino-5-carboxyvaleramido-(5-formyl-4-carboxy-2H, 3H, 6H-tetrahydro-1, 3-thiazinyl) glycine by spectral analyses, elucidation of hydrolysis products of the compound, and comparison of characteristics of the compound with those of a synthetic authentic compound.
\end{abstract}

We derived cephalosporin C (CPC)-negative mutants from Cephalosporium acremonium ATCC 14553 by $\mathrm{N}$-methyl- $\mathrm{N}^{\prime}$-nitro-N-nitrosoguanidine treatment, and demonstrated that some of the mutants exclusively accumulated deacetylcephalosporin $\mathrm{C}$ (DCPC) in the culture broth., ${ }^{1,2)} \mathrm{A}$ further survey of UV-absorbing substances present in the culture broths revealed that these DCPC-producing mutants accumulated an unknown compound (C-2).

In the present paper, the isolation and the elucidation of the chemical structure of the compound $\mathrm{C}-2$ are described.

\section{Materials and Methods}

Microorganism

The DCPC-producing mutant No. 40, ${ }^{1,2)}$ which was derived from Cephalosporium acremonium No. 52-54, was used throughout this investigation.

Media and cultivation

The composition of the media and culture conditions were the same as reported elsewhere.2) Determination of DCPC and compound C-2

An aliquot of a culture filtrate was subjected to electrophoresis $(95 \mathrm{~V} / \mathrm{cm}, 30 \mathrm{~min})$ in $0.1 \mathrm{M}$

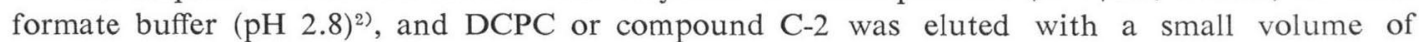
$0.01 \mathrm{M}$ potassium phosphate buffer ( $\mathrm{pH}$ 7.0) from the corresponding zone. Deacetyl-CPC and compound C-2 were determined by measuring the absorbance of the eluates at $261 \mathrm{~nm}$ and $301 \mathrm{~nm}$, respectively.

Thin-layer chromatography

Thin-layer chromatography was performed at room temperature on thin-layer cellulose plates (E. Merck, layer thickness $0.1 \mathrm{~mm}, 20 \times 20 \mathrm{~cm}$ ). The following solvent systems were used: (A) $n$-butanol-acetic acid-water $(3: 1: 1, \mathrm{v} / \mathrm{v})$; (B) $n$-propanol-water $(7: 3 . \mathrm{v} / \mathrm{v})$; (C) acetonitrile water $(8: 2, \mathrm{v} / \mathrm{v}) ;(\mathrm{D})$ isopropanol - water - pyridine $(65: 30: 5 . \mathrm{v} / \mathrm{v})$; (E) methanol - $n$-propanol - water $(6: 2: 1, \mathrm{v} / \mathrm{v}) ;(\mathrm{F})$ ethyl acetate - acetone - water $(2: 4: 2, \mathrm{v} / \mathrm{v})$.

Determination of amino acid component of compound C-2

After compound $\mathrm{C}-2$ was hydrolyzed with $6 \mathrm{~N} \mathrm{HCl}$ for 24 hours at $105^{\circ} \mathrm{C}$ in a sealed tube, a small portion of the hydrolyzate was subjected to the amino acid analyzer. 
Synthesis of D-5-( $t$-butyl-benzoyl)amino-5-carboxyvaleramido-(5-formyl-4-carboxy- $2 \mathrm{H}, 3 \mathrm{H}, 6 \mathrm{H}-$ tetrahydro-1,3-thiazinyl)glycine (IV)

Compound IV was synthesized according to the modified method of Terao et al. ${ }^{3)}$ in the following manner. $t$-Butyl-benzoyl $\mathrm{CPC}$ (I) was used as a starting compound. Disodium salt of $\mathbf{I}(1.00 \mathrm{~g})$ was dissolved in $20 \mathrm{ml}$ of $0.01 \mathrm{~m}$ potassium phosphate buffer ( $\mathrm{pH} 7.2$ ), to which lipase Saiken $100(1.60 \mathrm{~g})$ was added. The mixture was stirred at $30^{\circ} \mathrm{C}$ for 16 hours, and then passed through a Millipore filter. The filtrate was applied on a column of Amberlite XAD-2 $(3.5 \times 55 \mathrm{~cm})$. After the column was washed with distilled water, $t$-butyl-benzoyl DCPC (II) was eluted with $5 \%$ aqueous ethanol $(\mathrm{v} / \mathrm{v})$. The fractions containing II were pooled and concentrated in vacuo. The concentrate was lyophilized to give $800 \mathrm{mg}$ of powdery II. II $(600 \mathrm{mg})$ was suspended in $10 \mathrm{ml}$ of acetone and the resultant suspension was stirred at $5^{\circ} \mathrm{C}$. Then, an aliquot $(0.4 \mathrm{ml})$ of the solution $(15 \mathrm{ml})$ containing $2.67 \mathrm{~g}$ of chromic anhydride and $4.52 \mathrm{ml}$ of concentrated sulfuric acid was added dropwise over a period of 3 minutes, followed by stirring for a further 20 minutes at $5^{\circ} \mathrm{C}$. After the reaction was completed, a major portion of the acetone was distilled off, followed by the addition of distilled water $(10 \mathrm{ml})$. Extraction with ethylacetate $(30 \mathrm{ml})$ was performed three times. The combined extracts were dried over anhydrous $\mathrm{Na}_{2} \mathrm{SO}_{4}$, and the solvent was removed in vacuo to give $320 \mathrm{mg}$ of $7 \beta-[\mathrm{D}-5$-( $t$-butyl-benzoyl)amino5-carboxyvaleramido]-9-oxo-11-hydroxy-11H-furano[4,3-c]-3-cephem (III). III (300 mg) was dissolved in a small volume of acetone, to which $\mathrm{NaHCO}_{3}(350 \mathrm{mg})$ was added. After stirring for 1 hour at room temperature, the solution was applied to a column of Amberlite XAD-2 $(3.4 \times 43 \mathrm{~cm})$ and the column was washed with distilled water. Fractions containing $301 \mathrm{~nm}$ absorbing substance were collected and lyophilized to give $150 \mathrm{mg}$ of $\mathbf{D}-5$-( $t$-butyl-benzoyl)amino5-carboxyvaleramido-(5-formyl-4-carboxy-2H, 3H, 6H-tetrahydro-1, 3-thiazinyl)glycine (IV).

\section{Synthesis of $t$-butyl-benzoyl compound C-2}

Compound C-2 $(220 \mathrm{mg})$ was dissolved in a small volume of distilled water, the $\mathrm{pH}$ of the solution was adjusted to 9.0 by the addition of $1 \mathrm{~N} \mathrm{NaOH}$, and acetone solution of $p$ - $(t$-butyl)benzoyl chloride $(110 \mathrm{mg})$ added dropwise over a period of 1 hour. The mixture was stirred at room temperature for another 1 hour at $\mathrm{pH} 8.5 \sim 9.0$. Thereafter, the $\mathrm{pH}$ was brought to 7.5 by the addition of phosphoric acid and the major portion of the acetone was distilled off in vacuo. The concentrate was applied on a column of Amberlite XAD-2 $(3.5 \times 43 \mathrm{~cm})$ and the column was washed with distilled water. The fractions containing $301 \mathrm{~nm}$ absorbing substance were combined and lyophilized to give $120 \mathrm{mg}$ of $t$-butyl-benzoyl compound C-2.

Analytical methods

Amino acid analysis was performed by means of a Hitachi Model KLA-3B automatic amino acid analyzer. The UV spectrum was measured by a Hitachi Model 124 spectrophotometer. The IR spectrum was obtained with a Perkin-Elmer Model 21 infrared spectrometer. The NMR spectrum $(100 \mathrm{MHz})$ was recorded on a Varian HA-100 spectrometer. Optical rotation measurement was made with a Perkin-Elmer Model 141 polarimeter.

Materials

Saiken 100 lipase was purchased from Osaka Saikin Kenkyusho. DEAE-Sephadex A-25 and Sephadex G-10 were obtained from Pharmacia Fine Chemicals. Amberlite XAD-2 was purchased from Rohm \& Haas.

\section{Results}

Accumulation of an Unknown Compound (C-2) in the Culture Broths of DCPC-producing Mutants

In the course of studies on metabolites of mutants of Cephalosporium acremonium ATCC 14533 , it was found that UV-absorbing and ninhydrin-positive compound (C-2) accumulated in the culture broths of DCPC-producing mutants Nos. 20, 29, 36 and 40.1,2) As can be seen in Fig. 1, the accumulation of DCPC by these mutants was necessarily accompanied by that of 
compound $\mathrm{C}-2$, while the parent strain did not produce compound $\mathrm{C}-2$. In addition, when the mutants were cultivated in the fermentation medium without DL-methionine, neither DCPC nor compound $\mathrm{C}-2$ was formed in the culture broth. These data suggested the possibility that compound $\mathrm{C}-2$ might be formed from DCPC.

Time Course of Compound C-2 Accumulation by the Mutant No. 40

The time course of compound $\mathrm{C}-2$ production by mutant No. 40 was investigated. As shown in Fig. 2, compound C-2 began to be accumulated simultaneously with DCPC at the fourth day, and $160 \mu \mathrm{g} / \mathrm{ml}$ of compound C-2 was accumulated together with $850 \mu \mathrm{g} / \mathrm{ml}$ of DCPC after 7 days of cultivation.

\section{Isolation of Compound $\mathrm{C}-2$}

The 7-day culture broth (5 liters) of the

Fig. 1. Paper electrophoregram of metabolites in culture broths of Cephalosporium acremonium. Paper electrophoresis on Whatman No. 1 filter paper was performed in $0.1 \mathrm{M}$ formate buffer (pH 2.8) at $95 \mathrm{~V} / \mathrm{cm}$ for 30 minutes. Metabolites were detected by their absorption of ultraviolet light (solid line) and coloration with ninhydrin (dotted line).

(1) Authentic CPC, (2) authentic DCPC, (3) culture broth of the mutant No. 20, (4) culture broth of the mutant No. 40, (5) culture broth of the parent No. 52-54.

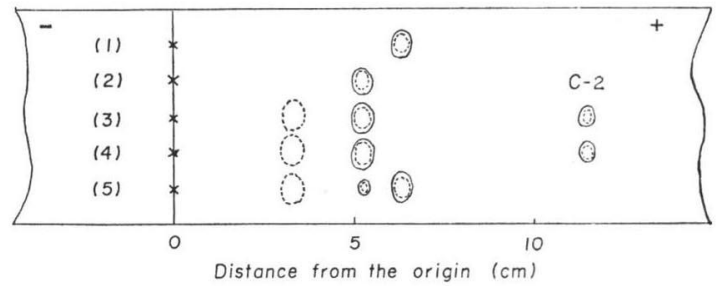
mutant No. 40 was centrifuged at $10,400 \times g$ for 10 minutes. The $\mathrm{pH}$ of the supernatant $(3.7$ liters) thus obtained was adjusted to 5.6 with $1 \mathrm{~N} \mathrm{HCl}$ and the solution was then passed through an activated carbon column $(8 \times 55 \mathrm{~cm})$. After the column was washed with distilled water, the adsorbed substances were eluted with 7.5 liters of $60 \%$ acetone containing $0.004 \mathrm{~N} \mathrm{NH}_{4} \mathrm{OH}$. The eluate was concentrated to $100 \mathrm{ml}$ in vacuo below $40^{\circ} \mathrm{C}$. The concentrate was applied on a DEAE-Sephadex A-25 column $(3.5 \times$ $23.5 \mathrm{~cm}$ ) equilibrated with $0.1 \mathrm{M}$ Tris- $\mathrm{HCl}$ buffer $(\mathrm{pH} 7.2)$. After the column was washed with $400 \mathrm{ml}$ of the same buffer, compound C-2 was eluted with a continuous salt gradient method from zero to $1.0 \mathrm{M} \mathrm{NaCl}$ in the buffer (Fig. 3). Frations containing compound C-2 (tube Nos.

Fig. 2. Time course of the production of compound $\mathrm{C}-2$ by the mutant No. 40.

The medium was composed of sucrose $3.0 \%$, soy bean flour $3.2 \%$, DL-methionine $0.5 \%$ and $\mathrm{CaCO}_{3} 0.15 \%$.

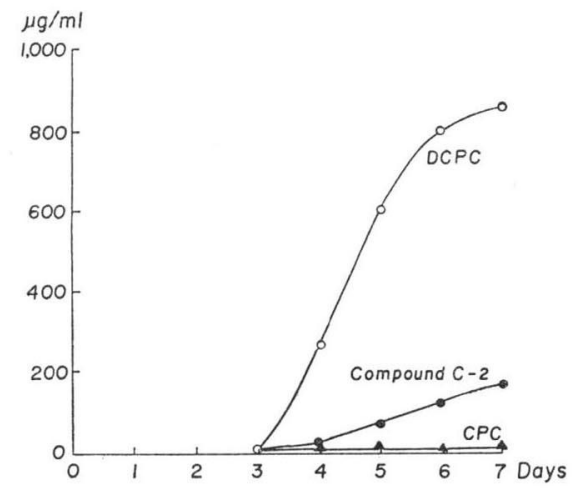

Fig. 3. Column chromotography of compound C-2 on DEAE-Sephadex A-25.

The concentrated preparation obtained by activated carbon column chromatography was applied on a column $(3.5 \times 23.5 \mathrm{~cm})$ and chromatographed at room temperature with a flow rate of $113 \mathrm{ml} / \mathrm{hr}$.

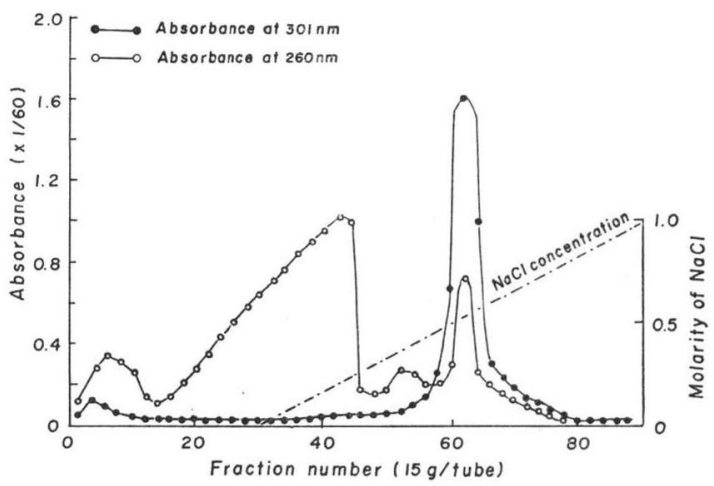


$60 \sim 70)$ were pooled, and then adsorbed on an activated carbon column $(3.0 \times 22.0 \mathrm{~cm})$ after the $\mathrm{pH}$ of the fractions was adjusted to 5.5 with $1 \mathrm{~N} \mathrm{HCl}$. The column was washed well with distilled water, and then compound C-2 was eluted with $500 \mathrm{ml}$ of $0.01 \mathrm{~N} \mathrm{NaOH}$ containing $7 \% n$-butanol. The eluate was concentrated to $3 \mathrm{ml}$ in vacuo. The concentrate was passed through a Sephadex G-10 column $(3.0 \times 137 \mathrm{~cm})$ and compound C-2 was eluted with distilled water. Gel filtration was repeated with the same column. Compound C-2 fractions were combined and lyophilized to give $170 \mathrm{mg}$ of a colorless powder.

\section{Characterization and Identification of Compound $\mathrm{C}-2$}

The purified compound $\mathrm{C}-2$ decomposed at above $162^{\circ} \mathrm{C}$ and was found to have the composition, $\mathrm{C}_{14} \mathrm{H}_{25} \mathrm{~N}_{3} \mathrm{SO}_{11}$ by elementary analysis:

Anal. Calcd. for $\mathrm{C}_{14} \mathrm{H}_{19} \mathrm{~N}_{3} \mathrm{SO}_{8} \cdot 3 \mathrm{H}_{2} \mathrm{O}$ : Found:

C, 37.92; H, 5.68; N, 9.48; S, 7.23; O, 39.69.

C, 36.66; H, 5.53; N, 11.14; S, 6.29; O, 40.38.

Compound $\mathrm{C}-2$ showed $[\alpha]_{\mathrm{D}}^{20}-52.1^{\circ}\left(c 1.0, \mathrm{H}_{2} \mathrm{O}\right)$ and was positive to ninhydrin, GreIGLEABACK, iodized starch, $\mathrm{FeCl}_{3}-\mathrm{K}_{3}\left[\mathrm{Fe}(\mathrm{CN})_{6}\right], \mathrm{AgNO}_{3}$ and Molisch's tests, and negative to anthrone reagent. The data suggested that compound $\mathrm{C}-2$ possessed both reducing and amino groups.

Hydrolysis of compound $\mathrm{C}-2$ with $6 \mathrm{~N} \mathrm{HCl}$ yielded an equimolar amount of $\alpha$-aminoadipic acid. The hydrolyzate of compound C-2 $(100 \mathrm{mg})$ was then adsorbed on a Dowex $50 \times 8\left(\mathrm{H}^{+}\right.$, $100 \sim 200$ mesh) column $(1.3 \times 22.0 \mathrm{~cm})$ equilibrated with $1 \mathrm{~N} \mathrm{HCl}$ and the column was washed with the acid according to the method of Hirs et al. ${ }^{4)}$ The $\alpha$-aminoadipic acid fractions were collected and evaporated to dryness in vacuo. The amino acid was crystallized from aqueous solution and its optical configuration was $[\alpha]_{\mathrm{D}}^{25}-20^{\circ}(c 1.0,1 \mathrm{~N} \mathrm{HCl})$.

The UV spectrum of compound $\mathrm{C}-2$ in $0.01 \mathrm{~m}$ potassium phosphate buffer at $\mathrm{pH} 7.0$ showed $\lambda_{\max }$ at $301 \mathrm{~nm}$ with $\mathrm{E}_{\mathrm{com}}^{\mathrm{\%}} 198$ (Fig. 4), and did not change by the addition of cephalosporinase ${ }^{2)}$

Fig. 4. UV absorption spectrum of compound C-2 $(50 \mu \mathrm{g} / \mathrm{ml})$ in $0.01 \mathrm{M}$ potassium phosphate buffer ( $\mathrm{pH}$ 7.0).

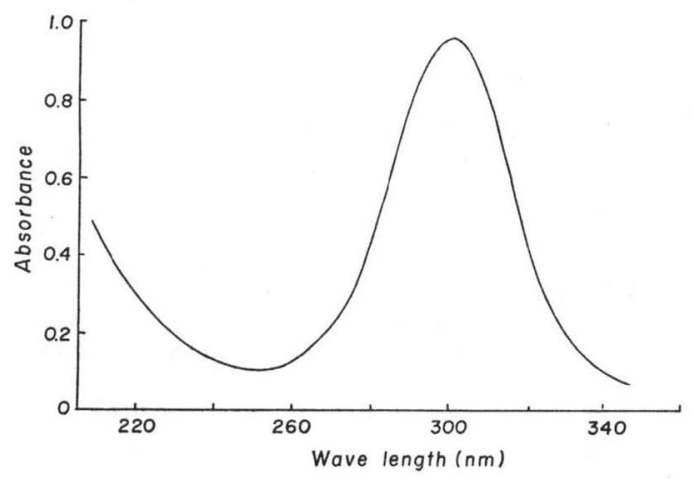

from the mutant No. 3 of Aerobacter cloacae IFO 12937. Its IR spectrum also showed no bands corresponding to $\beta$-lactam bond at near $1750 \mathrm{~cm}^{-1}$ (Fig. 5). Therefore, it seems that compound $\mathrm{C}-2$ does not have a $\beta$-lactam ring. As shown in Fig. 6, the NMR spectrum of compound $\mathrm{C}-2$ in $\mathrm{D}_{2} \mathrm{O}$ reveals the existence of a formyl group at $9.24 \mathrm{ppm}(1 \mathrm{H}, \mathrm{s})$. Signals at $1.7 \sim 2.4(4 \mathrm{H}, \mathrm{m})$ and $2.50(2 \mathrm{H}, \mathrm{t}$, $\mathbf{J}=7 \mathrm{~Hz}$ ) are assigned to $\alpha$-aminoadipic acid.

From the above data, compound $\mathrm{C}-2$ was presumed to be the cephalosporoate of 7 - (5 -amino-5 - carboxy pentamido) - 3 -formyl-3-

cephem-4-carboxylic acid. This chemical structure was finally proved by comparison of $t$-butylbenzoyl compound C-2 with IV synthesized from I (Fig. 7). IV was essentially identical with $t$-butyl-benzoyl compound C-2 in UV, IR, and NMR spectra, and chromatographic behavior (Table 1). Consequently, compound C-2 was concluded to be D-5-amino-5-carboxyvaleramido(5-formyl-4-carboxy-2H, 3H, 6H-tetrahydro-1, 3-thiazinyl)glycine. 
Fig. 5. IR absorption spectrum of compound $\mathrm{C}-2$ in $\mathrm{KBr}$ disk.

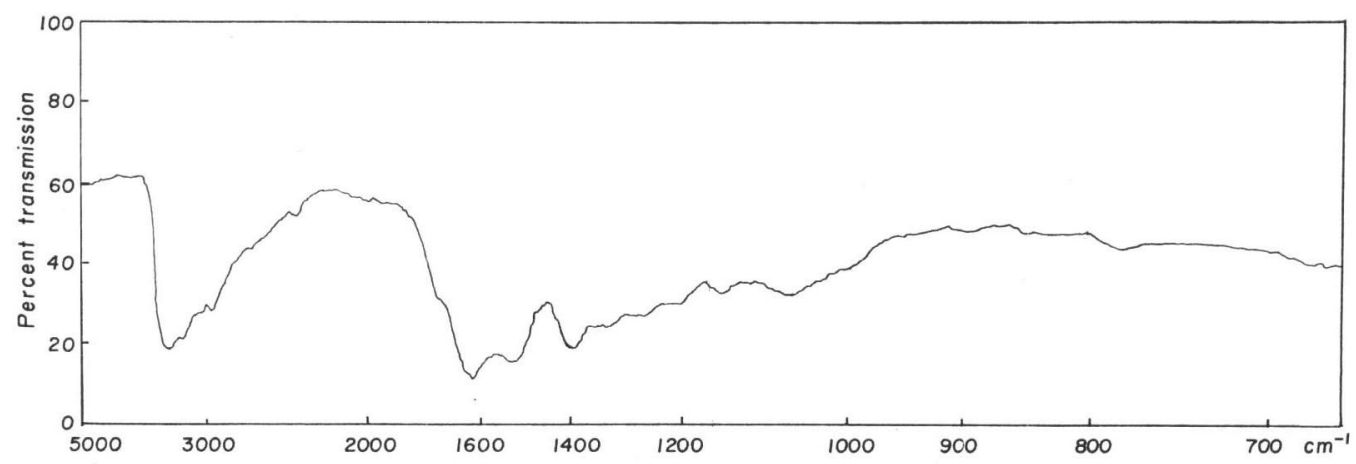

Fig. 6. NMR spectrum of compound $\mathrm{C}-2$ in $\mathrm{D}_{2} \mathrm{O}$ at $100 \mathrm{MHz}$.
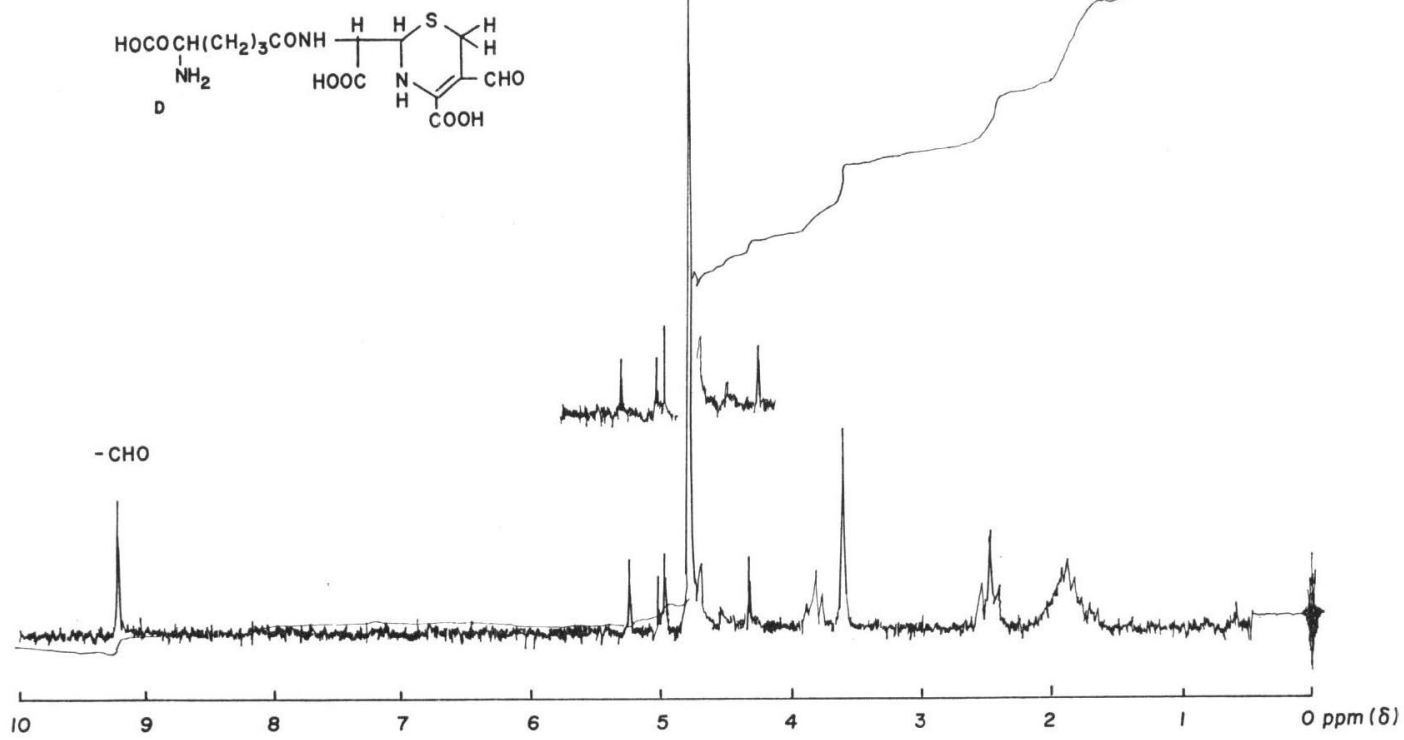

\section{Discussion}

On the basis of the studies on the elucidation of the mechanism of the cleavage of the $\beta$-lactam ring of cephalosporins by UVabsorption spectroscopy and the conventional chemical method, Hamilton-Miller et al. ${ }^{5)}$ stated that the above cleavage was accompanied by changes in the dihydrothiazine ring, and a tentative structure was proposed for the compound which had $\lambda_{\max } 230 \mathrm{~nm}$. They also reported that the cleavage pattern of cephalosporins in which $\mathrm{C}-3$ side chain was a leaving group, such as acetoxy or pyridinium, was different from that of DCPC lactone. That is to say the opening of the $\beta$-lactam of the lactone by mild hydrolysis appeared to
Table 1. Thin-layer chromatography of $t$-butylbenzoyl compound C-2 and authentic compound IV.

\begin{tabular}{c|c|c}
\hline \multirow{2}{*}{$\begin{array}{c}\text { Solvent } \\
\text { system }\end{array}$} & \multicolumn{2}{|c}{ Rf value } \\
\cline { 2 - 3 } & $\begin{array}{c}t \text {-Butyl-benzoyl } \\
\text { compound C-2 }\end{array}$ & $\begin{array}{c}\text { Authentic } \\
\text { compound IV }\end{array}$ \\
\cline { 2 - 3 } A & 0.82 & 0.83 \\
B & 0.59 & 0.59 \\
C & 0.46 & 0.45 \\
D & 0.66 & 0.67 \\
E & 0.48 & 0.47 \\
F & 0.84 & 0.85 \\
\hline
\end{tabular}

Solvent systems were described in the text. 
Fig. 7. Synthetic scheme of $t$-butyl-benzoyl compound C-2 and authentic compound IV.
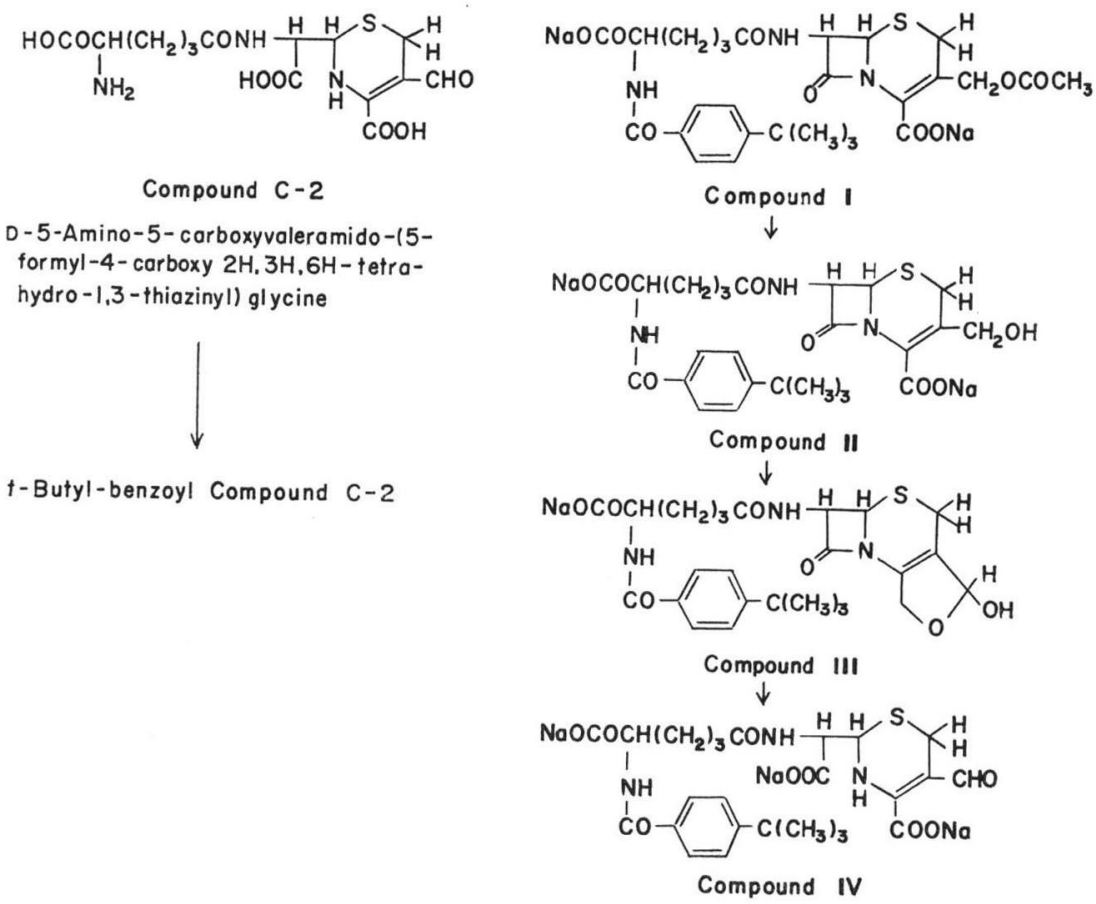

occur without other changes in the structure and the resulting product, which showed $\lambda_{\max } 265$ $\mathrm{nm}$, could be regarded as the corresponding cephalosporoate.

Compound C-2 is a new cephalosporoate in which the $\beta$-lactam of tentative 7-(5-amino-5carboxypentamido)-3-formyl-3-cephem-4-carboxylic acid was probably opened due to its instability at near neutral $\mathrm{pH}$. Compound $\mathrm{C}-2$ was found to be accumulated only in the culture broths of mutants Nos. 20, 29, 36 and 40, which were defective in acetyl CoA:DCPC acetyltransferase and therefore could not accumulate CPC but could accumulate DCPC. ${ }^{1)}$ Preliminary experiments indicated that a trace amount of compound $\mathrm{C}-2$ was detected in the mycelia of all the above DCPC-producing mutants and the CPC-producing parent strain No. 52-54. It seems possible that DCPC was probably oxidized intracellularly to 7-(5-amino-5-carboxypentamido)-3-formyl-3cephem-4-carboxylic acid, the $\beta$-lactam ring opened to form compound $\mathrm{C}-2$, and then compound $\mathrm{C}-2$ was excreted into the culture medium. The possibility was discounted that compound C-2 was derived from cephalosporoate of DCPC, because the opening of the $\beta$-lactam ring of DCPC resulted in the formation of the compound with $\lambda_{\max } 230 \mathrm{~nm}$, which was subject to more extensive cleavage.

\section{Acknowledgements}

We thank Drs. S. TAtsuoka, R. TAkeda, M. Isono and H. Fukuda, Takeda Chemical Industries, Ltd., for their interest and encouragement during the study. We also thank Drs. M. NumATA and S. Terao, Central Research Division, Takeda Chemical Industries, Ltd., for the preparation of $t$-butylbenzoyl CPC and valuable advice.

\section{References}

1) Fujisawa, Y.; H. Shirafuji, M. Kida, K. Nara, M. Yoneda \& T. Kanzaki: New findings on cephalosporin C biosynthesis. Nature, New Biol. 246: 154 155, 1973

2) Fujisawa, Y.; H. Shirafuji, M. Kida, K. Nara, M. Yoneda \& T. Kanzaki: Accumulation of 
deacetylcephalosporin $\mathrm{C}$ by cephalosporin $\mathrm{C}$ negative mutants of Cephalosporium acremonium. Agr. Biol. Chem. in press

3) Terao, S.; M. Shiraishi, T. Miyawaki, M. Numata, Y. Imashiro, I. Minamida \& M. Yamaoka: Process for producing lactol-type cephalosporins. Japanese Patent No. 123601, 1972

4) Hirs, C. H. W.; S. Moore \& W. H. Stein: The chromatography of amino acids on ion exchange resins. J. Am. Chem. Soc. 76: 6063 6065, 1954

5) Hamilton-Miller, J. M. T.; G. G. F. Newton \& E. P. Abraham: Products of aminolysis and enzymic hydrolysis of the cephalosporins. Biochem. J. 116: 371 384, 1970 